Article

\title{
Cutting Force during Surface Layer Milling of Selected Aluminium Alloys
}

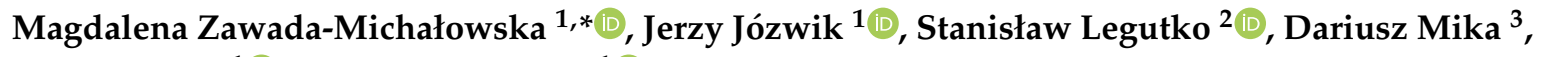 \\ Paweł Pieśko ${ }^{1}$ (D) and Jarosław Pytka ${ }^{1}$ (D) \\ 1 Faculty of Mechanical Engineering, Lublin University of Technology, 20-618 Lublin, Poland; \\ j.jozwik@pollub.pl (J.J.); p.piesko@pollub.pl (P.P.); j.pytka@pollub.pl (J.P.) \\ 2 Faculty of Mechanical Engineering, Poznan University of Technology, 60-965 Poznań, Poland; \\ stanislaw.legutko@put.poznan.pl \\ 3 Institute of Technical Sciences and Aviation, The State School of Higher Education in Chelm, 22-100 Chełm, \\ Poland; dmika@pwsz.chelm.pl \\ * Correspondence: m.michalowska@pollub.pl; Tel.: + 48-81-5384227
}

Received: 11 November 2020; Accepted: 13 December 2020; Published: 15 December 2020

check for updates

\begin{abstract}
This paper presents the analysis of cutting force during surface layer milling of selected aluminium alloys, which are widely used in the aviation industry. The cutting force is one of the most important parameters determining the machinability of the material and also provides important information about the course of the cutting. The study analysed the influence of the technological parameters, i.e., cutting speed $v_{c}$ and depth of cut $a_{p}$ as well as the relation between cutting tool feed direction and rolling direction on the value of cutting force during milling of selected aluminium alloys, i.e., EN AW-2017A T451 and EN AW-2024 T351. The material anisotropy is a very important issue, since the engineering industry faces enormous problems related to the cutting of the tested materials that are usually supplied in the form of rolled plates. The surface layer was cut due to the fact that it accumulates the greatest residual stresses. The measurement process of cutting force was performed by using 9257B Kistler piezoelectric dynamometer. As part of the analysis of the results, the measurement uncertainty was also estimated, which was determined on the basis of two components obtained by using the A and B methods, respectively.
\end{abstract}

Keywords: aluminium alloys; cutting force; milling; surface layer

\section{Introduction}

The requirements related to, among others, with weight reduction while maintaining both high strength and stiffness are imposed on thin-walled aircraft parts. When manufacturing such parts, major difficulties arise in retaining appropriate dimensional and shape accuracy, since undesirable deformations appear after the completion of cutting and removal of the clamping force [1,2]. For this reason, measuring the cutting force, which is one of the factors connected to the aforementioned problem is an important aspect [3]. It should also be noted that due to the need to obtain high efficiency, High Speed Cutting is a widely used technique which is characterised by lower depth of cut $a_{p}$ and higher cutting speed $v_{c}$ compared to conventional machining [4].

Taking into account the fact that during cutting, the residual stresses are generated primarily as a result of the cutting force, the analysis of the obtained cutting force values with different technological parameters may be of vital importance for maintaining the required dimensional and shape accuracy [5]. Therefore, it is assumed that during machining, the main model of residual stress formation is the mechanical model. Apart from the cutting force mentioned, the residual stresses result from a number other factors, e.g., clamping force, temperature, etc. [6]. 
The cutting force is a parameter that determines the machinability of the material, and also provides important information related to the course of the cutting process [7]. On its basis it is possible to decide to change the technological parameters [8] as well as to state that the cutting blades have become worn [9]. Liang et al. [9] also noted that the cutting force provides information about the physical mechanics and dynamics of cutting processes. That is why measurement of the cutting force, especially in real time ("online"), is so significant [10].

It should be emphasised that the cutting force depends on many factors, including, for example, technological parameters [11,12], the properties of the workpiece material, tool material and geometry as well as the cooling method used [13].

Prediction of cutting force is a key issue, especially in terms of increase in production efficiency by maximising the volume of material removed. The dynamic development of numerical methods implies a search for theoretical ways of the cutting force determination. However, due to the complexity of the phenomena accompanying the cutting process, it is difficult to apply it in practice. A mechanistic model of the prediction of milling forces for serrated milling tools was presented in [14]. This type of cutting tool is increasingly used in 5-axis high-performance machining of complex parts. The proposed model applies to both static and dynamic conditions and it allows to take into account, for example, tool parameters and technological parameters. Tsai et al. [15] showed a new geometric force prediction model for ball-end cutter. It described, among others, tool geometry (rake angle), cutting speed and chip flow angle. Urbikain Pelayo [16] presented modelling of static and dynamic milling forces for circle-segment mills. Tool geometry, modal parameters and cutting condition are taken into account.

Currently, cutting force measurements are carried out mainly by two methods: indirect and direct. In the indirect method, the power or current of the spindle motor or the drive motor are measured and the cutting force is calculated on their basis. The direct measurements are performed when the measuring instrument is placed on the table or on the machine tool spindle and for this purpose a dynamometer is used, which is characterised by high repeatability and stability. Its principle of operation is to convert the cutting force into deformation and detect this deformation with flexible sensing elements. Currently, the most widely used are dynamometers, which in the case of instruments mounted on tables, are characterised by the fact that the flexible element has the shape of, among others: an octagonal ring, an oval octagonal ring or a ring. However, in dynamometers mounted on the machine tool spindle, the elastic part is a cylindrical beam, a $\Gamma$ beam-type or an E-type diaphragm $[10,17,18]$. As for the type of transducer, there are, inter alia, capacitive, strain gauge, piezoelectric and fibre Bragg grating (FBG) [19-21]. Due to the dynamics of the cutting processes and the subsequent signal analysis, piezoelectric dynamometers are currently used to measure the cutting forces [22].

Aluminium alloys have different machinability compared to other materials. It results mainly from their properties, such as: high coefficient of linear expansion, low Young's modulus and high thermal conductivity (in relation to steel). For aluminium alloys, the value of the cutting force is assumed to be about $30 \%$ of the value occurring in the machining of steel, but its precise determination requires experimental tests [23].

Rolled plates are widely used in manufacturing of thin-walled elements from wrought aluminium alloys. They are characterised by the phenomenon of anisotropy, i.e., having different mechanical properties depending on the rolling direction. In addition, the aforementioned anisotropy may cause deformations of parts with thin walls. It is so important to monitor cutting force in precision machining of these elements [24]. Zawada-Michałowska et al. [25] presented the removal of the textured surface layer as one of the pre-machining methods. This operation has a positive effect on minimising deformations of thin-walled elements.

The aim of the paper is to assess the changes in the cutting force as a function of cutting speed $v_{c}$, in particular to determine the minimum cutting force values that could occur during pre-machining consisting in removing the textured surface layer formed after the rolling process of plates made of wrought aluminium alloys. This is a very important issue in terms of the aforementioned residual stresses. 
Table 2. The chemical composition and selected properties of the EN AW-2024 T351 alloy [26,27].

\begin{tabular}{|c|c|c|c|c|c|c|c|c|c|c|}
\hline \multicolumn{11}{|c|}{ Chemical Composition (\%) } \\
\hline $\begin{array}{l}\mathrm{Si} \\
\leq 0.5\end{array}$ & $\begin{array}{l}\mathrm{Fe} \\
\leq 0.5\end{array}$ & $\begin{array}{c}\mathrm{Mg} \\
1.2-1.8\end{array}$ & $\begin{array}{c}\mathrm{Cu} \\
3.8-4.9\end{array}$ & $\begin{array}{c}\mathrm{Mn} \\
0.3-0.9\end{array}$ & $\begin{array}{l}\mathrm{Cr} \\
\leq 0.1\end{array}$ & $\begin{array}{c}\mathrm{Zn} \\
\leq 0.25\end{array}$ & $\begin{array}{c}\mathrm{Zr}+\mathrm{Ti} \\
\leq 0.2\end{array}$ & $\begin{array}{c}\mathrm{Ti} \\
\leq 0.15\end{array}$ & $\begin{array}{l}\text { Other } \\
\leq 0.15\end{array}$ & $\begin{array}{c}\text { Al } \\
\text { Rest }\end{array}$ \\
\hline \multicolumn{11}{|c|}{ Selected Properties } \\
\hline \multicolumn{2}{|c|}{$\begin{array}{c}\text { Density } \\
\rho\left(\mathrm{g} / \mathrm{cm}^{3}\right) \\
2.78\end{array}$} & \multicolumn{2}{|c|}{$\begin{array}{c}\text { Young modulus } \\
E(\mathrm{GPa}) \\
73\end{array}$} & \multicolumn{2}{|c|}{$\begin{array}{c}\text { Tensile strength } \\
R_{m}(\mathrm{MPa}) \\
469\end{array}$} & \multicolumn{2}{|c|}{$\begin{array}{l}\text { Yield strength } \\
R_{p 0.2}(\mathrm{MPa}) \\
324\end{array}$} & \multicolumn{3}{|c|}{$\begin{array}{l}\text { Brinell hardness } \\
\text { (HB) } \\
120\end{array}$} \\
\hline
\end{tabular}

The values of the technological parameters used are presented in Table 3.

Table 3. The technological parameters used.

\begin{tabular}{cccc}
\hline \multicolumn{3}{c}{ Technological Parameters } \\
\hline $\begin{array}{c}\text { Variable Depth of Cut } \\
\boldsymbol{a}_{\boldsymbol{p}}(\mathbf{m m})\end{array}$ & $\begin{array}{c}\text { Milling Width } \\
\boldsymbol{a}_{\boldsymbol{e}}(\mathbf{m m})\end{array}$ & $\begin{array}{c}\text { Feed Per Tooth } \\
f_{z}(\mathbf{m m} / \text { tooth })\end{array}$ & $\begin{array}{c}\text { Variable Cutting Speed } \\
\boldsymbol{v}_{\boldsymbol{c}}(\mathbf{m} / \mathbf{m i n})\end{array}$ \\
\hline- & & & 100 \\
0.1 & 20 & 0.05 & 500 \\
0.25 & & & 1000 \\
0.4 & & 1500 \\
\hline
\end{tabular}

Another analysed variable was rolling direction, i.e., the relation between the cutting tool feed direction and the rolling direction:

- perpendicular direction (milling direction was perpendicular to rolling direction),

- parallel direction (milling direction was parallel to rolling direction).

The cutting process was conducted using a coolant. An end mill (211811) of GARANT (Munich, Germany) was used for research. Table 4 shows the specification of the milling cutter.

Table 4. Specification of milling cutter [28].

\begin{tabular}{cc}
\hline Symbol & GARANT 211811 \\
\hline External diameter $D(\mathrm{~mm})$ & 32 \\
Number of teeth $z$ & 2 \\
Overall length $L(\mathrm{~mm})$ & 47 \\
Helix angle $\left(^{\circ}\right)$ & 8 \\
Rake angle $\left(^{\circ}\right)$ & 25 \\
Flank angle $\left(^{\circ}\right)$ & 7 \\
Cutting insert & VCGX 220508 FR HU 7810 (211856) \\
\hline
\end{tabular}

The measuring system used consisted of 9257B piezoelectric dynamometer of Kistler (Winterthur, Switzerland) connected to 5070A charge amplifier. The signal from the amplifier was sent to 5697A DAQ module and it was analysed using the dedicated DynoWare software (2825A, Kistler, Winterthur, Switzerland) [29]. Figure 2 presents the schematic diagram of the methodology.

Within the experiment, the analysis of the microstructures of the surface layer was also carried out for the tested relations between the milling direction and the rolling direction, as well as for the examined aluminium alloys. The Nikon Epiphot inverted metallographic microscope (Nikon, Tokyo, Japan) with the ToupView software was used. The aim of the analysis of the surface layer microstructures was to determine the thickness of the textured surface layer formed after rolling both EN AW-2017A T451 and EN AW-2024 T351. 


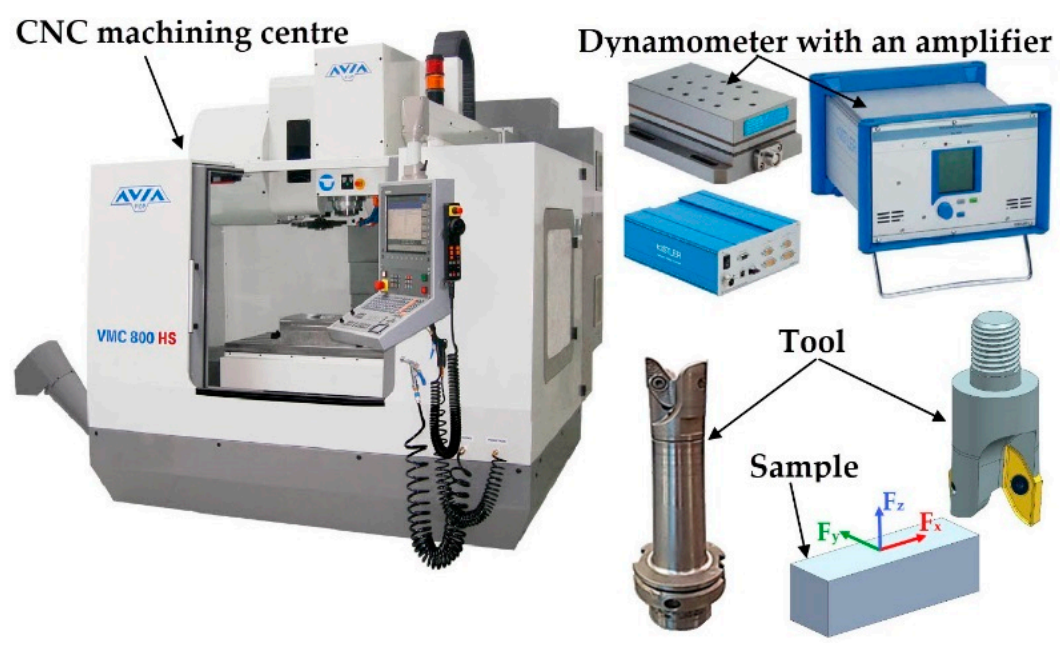

Figure 2. Schematic diagram of the methodology.

The tests were repeated five times. The number of repetitions was determined from Equation (1):

$$
n=\frac{t_{(\alpha ; f)}^{2} S_{x}^{2}}{\varepsilon^{2}}
$$

where: $S_{x}^{2}$-variance of the tested variable determined on the basis of the preliminary test results $\left(S_{x}^{2}=4.77\right), \varepsilon$-assessment accuracy ( $\varepsilon-5 \%$ of obtained average value, $\left.\varepsilon=2.5\right), t$-critical value of the Student's $t$-test $(t=2.262), \alpha$-significance level $(\alpha=0.05)$, and $f$-number of degrees of freedom $(f=9)$.

\section{Results}

The research began with the analysis of the microstructures of the surface layer formed after rolling for the tested relations between the milling direction and the rolling direction as well as for both aluminium alloys. Figures 3 and 4 show the microstructure images for EN AW-2017A T451 and EN AW-2024, respectively.

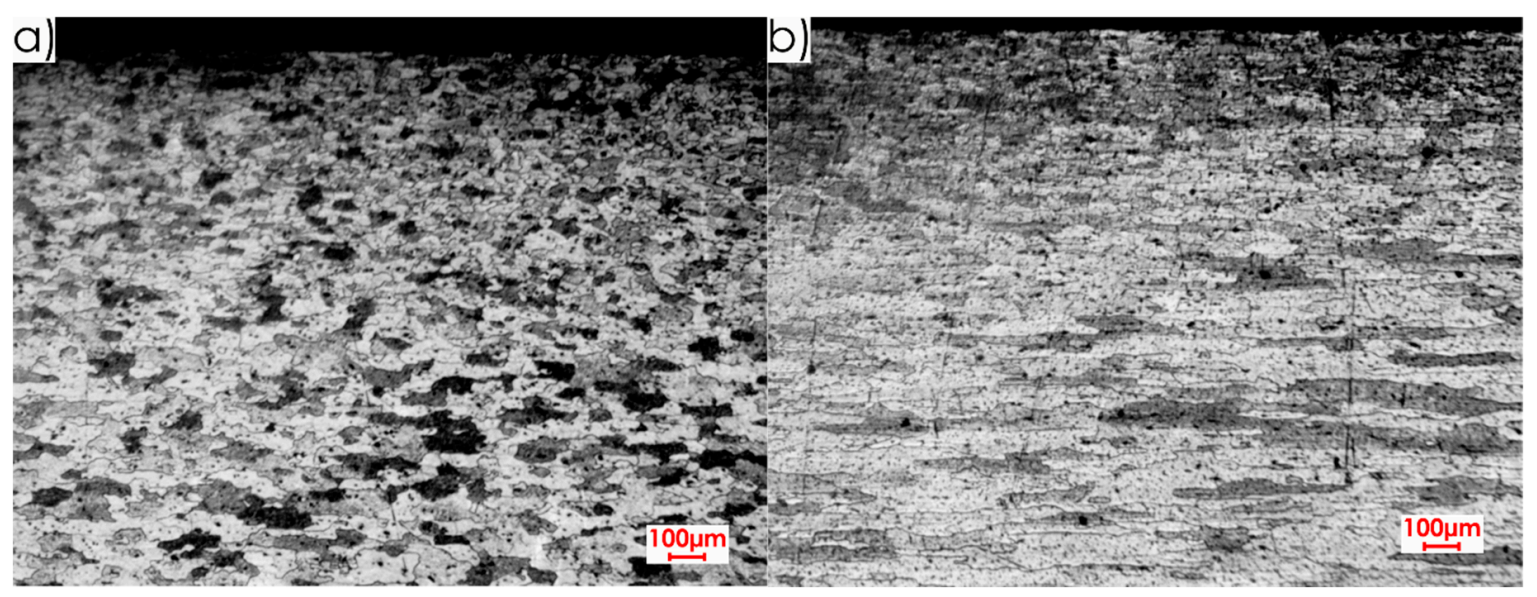

Figure 3. Microstructure of surface layer for EN AW-2017A T451 alloy: (a) perpendicular rolling direction, (b) parallel rolling direction (2.5× magnification). 


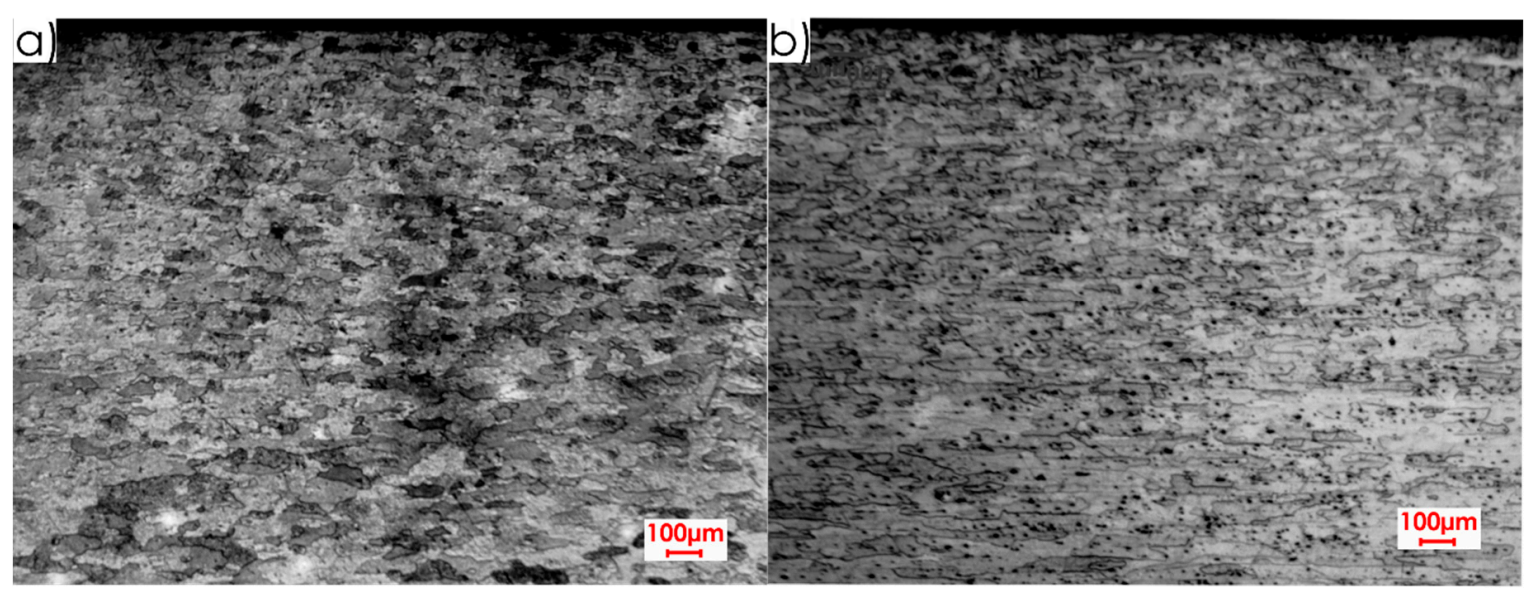

Figure 4. Microstructure of surface layer for EN AW-2024 T351 alloy: (a) perpendicular rolling direction,

(b) parallel rolling direction (2.5× magnification).

Analysing microstructures (Figures 3 and 4), a difference was found between the core and the surface layer. A clearly elongated grains were also observed in the rolling direction, especially in the core of the material. This statement is true for both alloys. In the case of EN AW-2017A T451, the textured surface layer is more visible (Figure 3) than for EN AW-2024 T351 (Figure 4). For EN AW-2017A $\mathrm{T} 451$, the grains in the area of the surface layer are significantly dense and fragmented in comparison to the material core and they do not have a clear orientation. A different situation can be observed in the case of the EN AW-2024 T351, i.e., there is no clear difference, especially in the perpendicular direction to the rolling direction, between the surface layer and the core. Some differences between the surface layer and the core for this alloy can be stated for the parallel direction to the rolling direction-the grains are finer and the structure is not clearly oriented in the surface layer. When comparing both alloys, it was found that the microstructure of EN AW-2017A T451 in the core is characterised by greater graininess and the thickness of surface layer is deeper (about $0.4 \mathrm{~mm}$ ) in comparison to EN AW-2024 T351, where it is approximately $0.25 \mathrm{~mm}$.

Based on the microstructure analysis (Figures 3 and 4), it was found that the thickness of the textured surface layer formed after rolling is from range 0.25-0.4 mm for EN AW-2017A T451 and EN AW-2024 T351 alloys. Hence, it was decided to remove the surface layer with the indicated values of depths of cut $a_{p}$ in the milling process. In the case of the cutting speed $v_{c}$, the values were selected by trying to conduct "delicate machining" (at $v_{c}=100 \mathrm{~m} / \mathrm{min}$ ) and at significantly higher values $\left(v_{c}=1000 \mathrm{~m} / \mathrm{min}\right.$ and $\left.v_{c}=1500 \mathrm{~m} / \mathrm{min}\right)$.

Figure 5 presents the values of the cutting force components $F_{x}, F_{y}, F_{z}$ for EN AW-2017A T451 alloy and analysed cutting speeds $v_{c}$ at $a_{p}=0.4 \mathrm{~mm}$. The recorded values of the cutting force components are the effect of various phenomena accompanying the cutting process. The study did not focus on all components of the cutting force and did not analyse the phenomena affecting their value, but only on determining the values of the cutting force depending on the selected technological parameters. In particular, it was bothered to establish for which cutting speed $v_{c}$, the cutting force has the lowest value. Lower cutting force is the result of lower cutting resistance, and thus also lower deformations and post-machining residual stresses. In the further part of the paper, the analysis of the component of the cutting force $F_{x}$, which had the highest values, in comparison to $F_{y}$ and $F_{z}$, was made. 


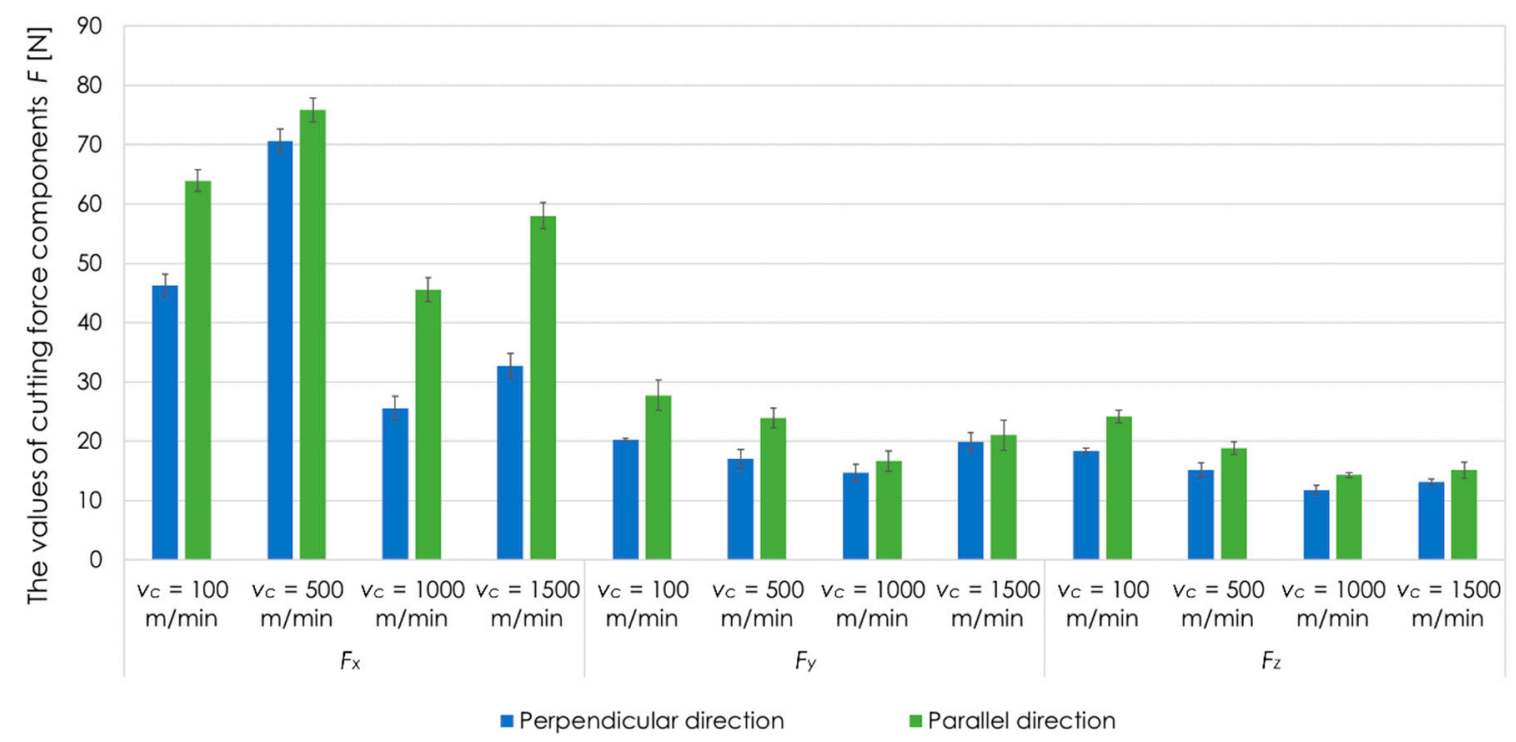

Figure 5. Cutting force components $F_{x}, F_{y}, F_{z}$, for EN AW-2017A T451 aluminium alloy, tested cutting speeds $v_{\mathcal{c}}$, perpendicular and parallel milling direction in relation to the rolling direction, $a_{p}=0.4 \mathrm{~mm}$.

Figure 6 presents the results of cutting force component $F_{x}$ for EN AW-2017A T451 aluminium alloy, tested cutting speeds $v_{c}$, depths of cut $a_{p}$ as well as perpendicular and parallel milling direction in relation to the rolling direction. Analysing the results, it was found that the highest value of cutting force component $F_{x}$ was recorded at $v_{c}=500 \mathrm{~m} / \mathrm{min}$, while the lowest one at $v_{c}=1000 \mathrm{~m} / \mathrm{min}$. These dependencies are true for all tested depths of cut $a_{p}$. For perpendicular rolling direction and $a_{p}=0.1 \mathrm{~mm}$, value of cutting force component $F_{x}$ at $v_{c}=1000 \mathrm{~m} / \mathrm{min}$ was lower by over $60 \%$ than at $v_{c}=500 \mathrm{~m} / \mathrm{min}$. For $a_{p}=0.25 \mathrm{~mm}$, the analogous difference was $40 \%$, while for $a_{p}=0.4 \mathrm{~mm}$, it was about $60 \%$. For parallel rolling direction and $a_{p}=0.1 \mathrm{~mm}$, the cutting force component $F_{x}$ was lower by about $60 \%$ at $v_{c}=1000 \mathrm{~m} / \mathrm{min}$ compared to $v_{c}=500 \mathrm{~m} / \mathrm{min}$. In the case of $a_{p}=0.25 \mathrm{~mm}$ and $a_{p}=0.4 \mathrm{~mm}$, the differences were about $40 \%$. Additionally, it was observed that higher values of the cutting force component $F x$ were obtained for parallel milling direction in comparison to perpendicular direction.

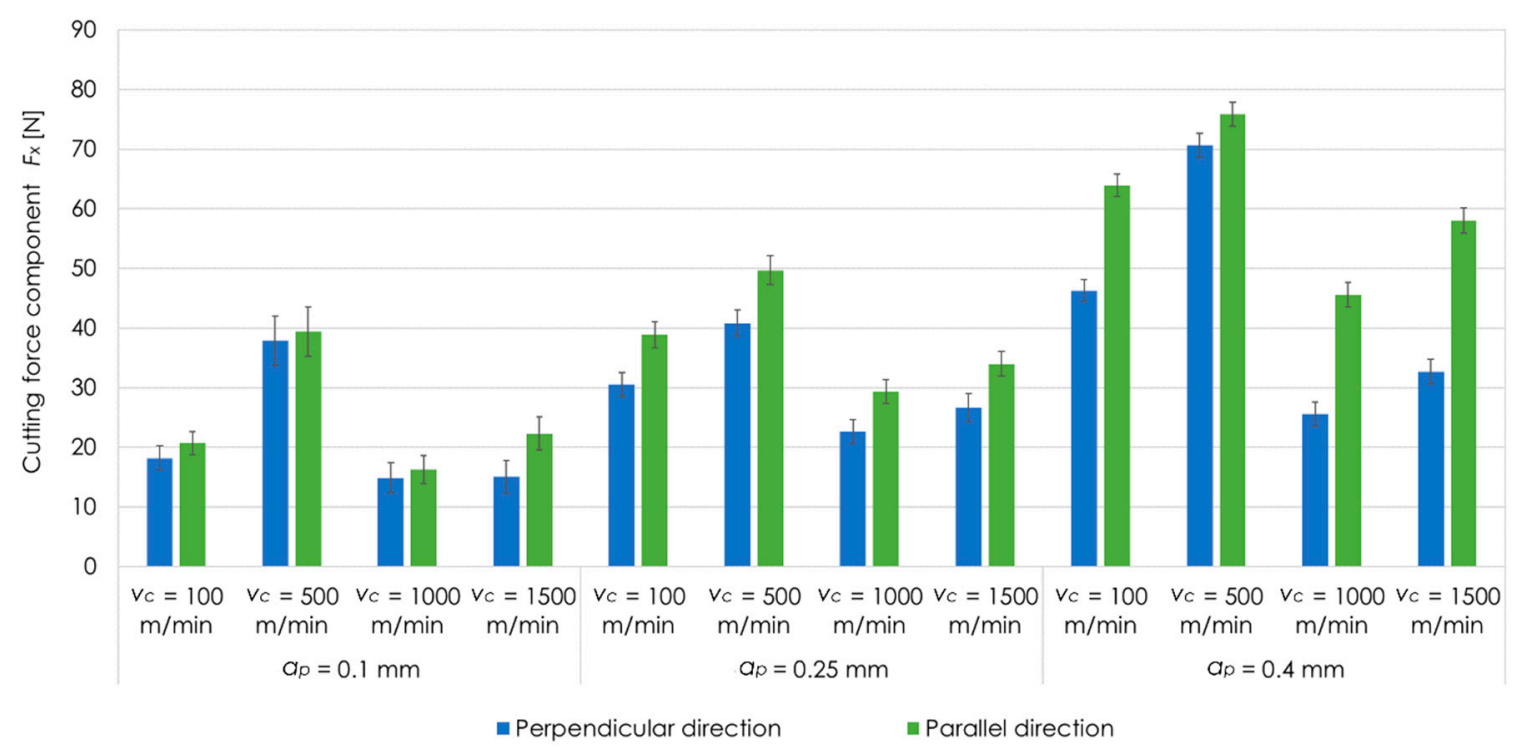

Figure 6. Cutting force component $F_{x}$ for EN AW-2017A T451 aluminium alloy, tested cutting speeds $v_{\mathcal{C}}$, depths of cut $a_{p}$ as well as perpendicular and parallel milling direction in relation to the rolling direction. 
Figure 7 presents the results of cutting force component $F_{x}$ for EN AW-2024 T351 aluminium alloy, analysed values of cutting speeds $v_{\mathcal{c}}$, depths of cut $a_{p}$ as well as perpendicular and parallel milling direction in relation to the rolling direction. On the basis of the results, it can be seen that for EN AW-2024 T351, the maximum values of the cutting force component $F_{x}$ were noted at $v_{c}=100 \mathrm{~m} / \mathrm{min}$, and the minimum one at $v_{c}=1500 \mathrm{~m} / \mathrm{min}$ for all tested depths of cut $a_{p}$. For perpendicular rolling direction and $a_{p}=0.1 \mathrm{~mm}$, value of cutting force component $F_{x}$ at $v_{c}=100 \mathrm{~m} / \mathrm{min}$ was higher by almost $30 \%$ in comparison to $v_{\mathcal{c}}=1500 \mathrm{~m} / \mathrm{min}$. For $a_{p}=0.25 \mathrm{~mm}$, it was $45 \%$, while for $a_{p}=0.4 \mathrm{~mm}$, it was over $50 \%$. The analogous dependence was reached for parallel rolling direction. For $a_{p}=0.1 \mathrm{~mm}$, the cutting force component $F_{x}$ was higher by almost $40 \%$ at $v_{c}=100 \mathrm{~m} / \mathrm{min}$ compared to $v_{c}=1500 \mathrm{~m} / \mathrm{min}$. In the case of $a_{p}=0.25 \mathrm{~mm}$ and $a_{p}=0.4 \mathrm{~mm}$, the differences were about $45 \%$ and $50 \%$, respectively. It was also observed that higher values of the cutting force component $F_{x}$ were received for parallel milling direction than for perpendicular direction.

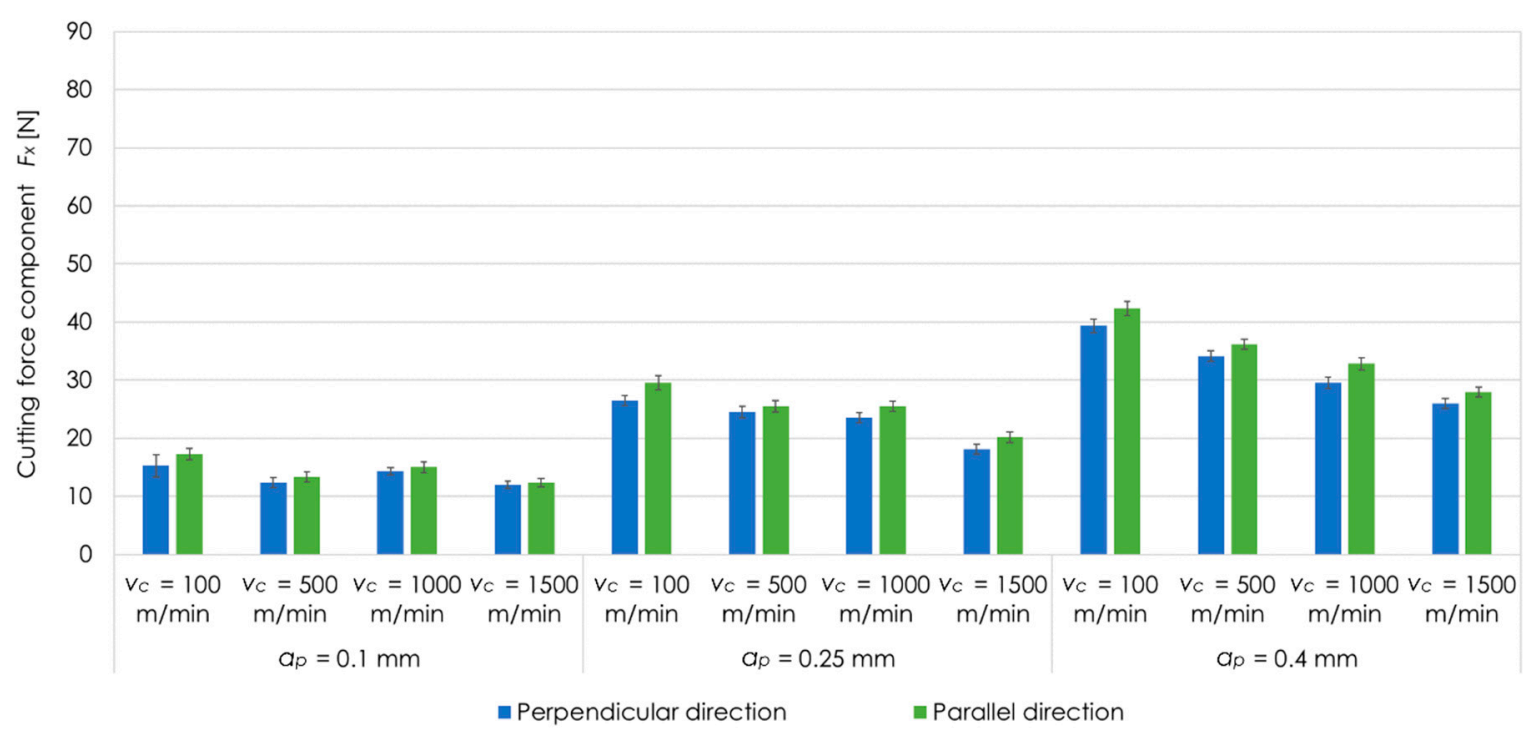

Figure 7. Cutting force component $F_{x}$ for EN AW-2024 T351 aluminium alloy, tested cutting speeds $v_{\mathcal{C}}$, depths of cut $a_{p}$ as well as perpendicular and parallel milling direction in relation to the rolling direction.

Figure 8 shows the comparison of cutting force component $F_{x}$ as a function of cutting speed $v_{c}$ for tested aluminium alloys (EN AW-2017A T451 and EN AW-2024 T351) as well as perpendicular and parallel relations between cutting tool feed direction and rolling direction at $a_{p}=0.1 \mathrm{~mm}$. On the basis of the results presented, it can be seen that for EN AW-2024 T351, the values of the cutting force component $F_{x}$ were lower in comparison to EN AW-2017A T451 for all examined cutting speeds $v_{c}$ and both relations between milling direction and rolling direction.

On the basis of changes in the cutting force as a function of the cutting speed $v_{\mathcal{C}}$ (Figures 5-8), it is possible to determine the limit of occurrence of High Speed Cutting. The original definition of HSC stated that it is machining at cutting speeds $v_{c} 5-10$ times, depending on the material to be machined, higher than the values used for conventional machining. Now there are new proposals for defining HSC. One of them introduces the concept of the so-called limit cutting speed $v_{c g r}$, from which the HSC range begins. Different criteria for the moment of HSC occurrence are applied. Some researchers assume that the HSC can be discussed when an increase in the cutting speed $v_{c}$ causes a decrease in the cutting forces, in the case of the research conducted, this limit corresponds to the speed $v_{c}=500 \mathrm{~m} / \mathrm{min}$ for EN AW-2017A T451 and $v_{c}=100 \mathrm{~m} / \mathrm{min}$ for EN AW-2024 T351. In other studies, it is assumed that the limit speed is the cutting speed to which the cutting force decreases significantly and then increases gently. In the case considered, this is speed of about $v_{c}=1000 \mathrm{~m} / \mathrm{min}$ for EN AW-2017A T451 and $v_{c}$ $=1500 \mathrm{~m} / \mathrm{min}$ for EN AW-2024 T351. The second way of defining HSC, especially when machining thin-walled parts, appears to be more appropriate, as it is important to minimise the cutting forces 
when machining this type of parts. It can therefore be determined that when machining such elements one ought to use HSC, ensuring minimisation of cutting forces.

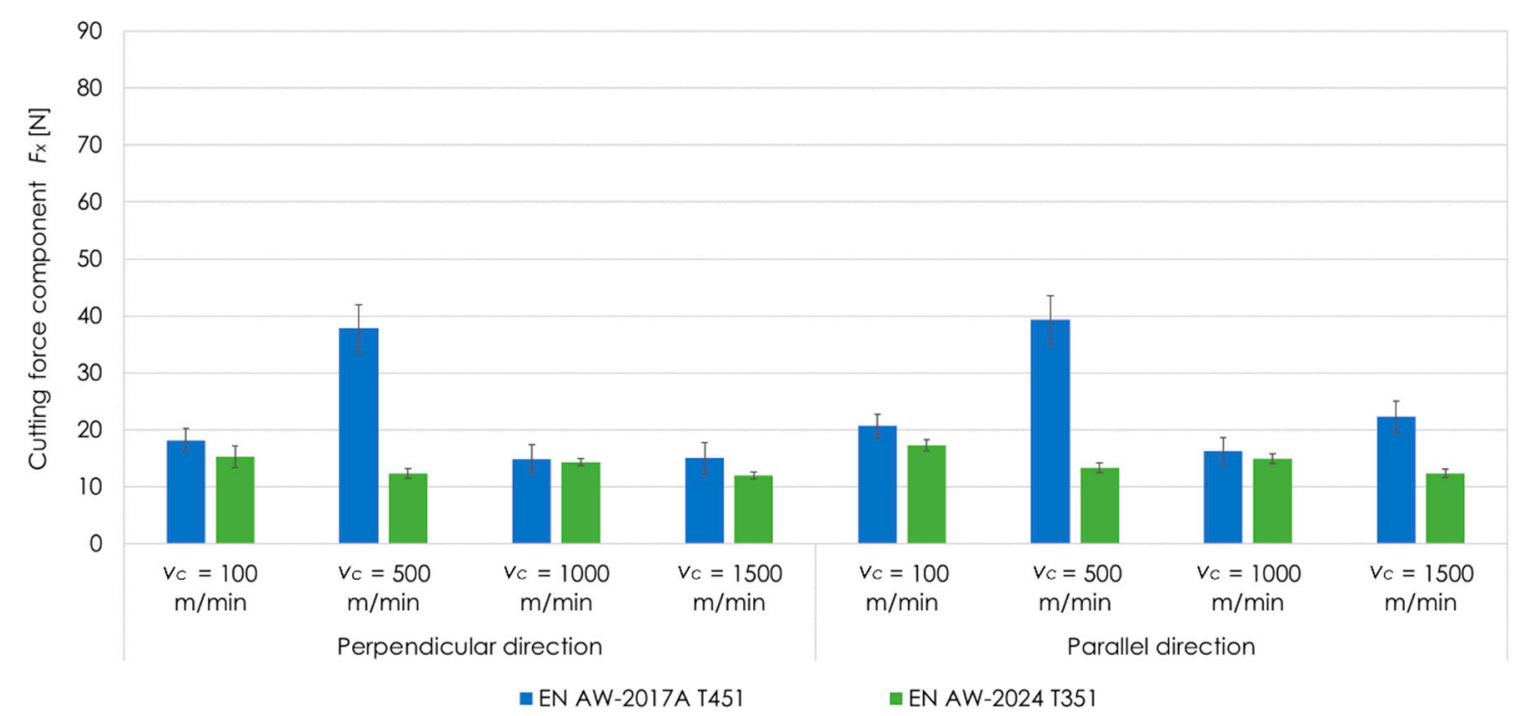

Figure 8. Comparison of cutting force component $F_{x}$ as a function of cutting speed $v_{\mathcal{C}}$ for tested aluminium alloys as well as perpendicular and parallel milling direction in relation to the rolling direction at $a_{p}=0.1 \mathrm{~mm}$.

An inseparable element of measurement is its uncertainty. It characterises the dispersion of the results obtained and it can be determined on the basis of two methods, i.e., A and B. The uncertainty component of A method is based on the statistical analysis of the measurement results, i.e., the calculation of the standard deviation of the mean, while the uncertainty component of B method takes into account the data included in the calibration certification of the measuring instrument used [3,30].

The estimation procedure of expanded uncertainty $U$ consists in to multiply the combined standard uncertainty $u_{c}$ by the expansion factor, in this case $k=2$, according to Equation (2).

$$
U= \pm k u_{c}
$$

Calculating the combined standard uncertainty $u_{c}$, it is necessary to take into account the component of standard uncertainty determined by A method $u_{A}$ and the components of the standard uncertainty assessed by B method $u_{B i}$ (Equation (3)).

$$
u_{c}= \pm \sqrt{u_{A}^{2}+\sum_{i=1}^{n} u_{B i}^{2}}
$$

In the case of measurement uncertainty component estimated by using B method, two factors should be taken into account, that is, resulting from the linearity $u_{B l}$ as well as from the hysteresis $u_{B h}$ (Equation (4)).

$$
\sum_{i=1}^{n} u_{B i}^{2}=u_{B l}^{2}+u_{B h}^{2}
$$

The combined standard uncertainty $u_{c}$ is therefore estimated according to Equation (5), having regard to all uncertainty components both from $\mathrm{A}$ and $\mathrm{B}$ methods.

$$
u_{c}= \pm \sqrt{u_{A}^{2}+u_{B l}^{2}+u_{B h}^{2}}
$$


As already mentioned, the uncertainty component estimation by B method is based on the data given in the calibration certificate of the instrument used, in this case the piezoelectric dynamometer. The standard uncertainty components resulting from linearity $u_{B l}$ is determined from Equation (6) and from the hysteresis $u_{B h}$ from Equation (7). In both cases, a rectangular distribution of measurement results was assumed.

$$
\begin{gathered}
u_{B l}= \pm \frac{1 \% \cdot F S O}{\sqrt{3}} \\
u_{B h}= \pm \frac{0.5 \% \cdot F S O}{\sqrt{3}}
\end{gathered}
$$

Tables 5 and 6 present estimated uncertainties and their components of A and B methods for perpendicular and parallel milling direction in relation to the rolling direction, selected depth of cut $a_{p}=0.4 \mathrm{~mm}$ as well as tested EN AW-2017A T451 and EN AW-2024 T351 aluminium alloys, respectively.

Table 5. Uncertainty and its components for EN AW-2017A T451, perpendicular and parallel milling

\begin{tabular}{|c|c|c|c|c|c|c|c|c|}
\hline \multirow{2}{*}{ Uncertainty } & \multicolumn{2}{|c|}{$v_{c}=100 \mathrm{~m} / \mathrm{min}$} & \multicolumn{2}{|c|}{$v_{c}=500 \mathrm{~m} / \mathrm{min}$} & \multicolumn{2}{|c|}{$v_{c}=1000 \mathrm{~m} / \mathrm{min}$} & \multicolumn{2}{|c|}{$v_{c}=1500 \mathrm{~m} / \mathrm{min}$} \\
\hline & $\perp$ & $\|$ & $\perp$ & $\|$ & $\perp$ & $\|$ & $\perp$ & $\|$ \\
\hline$u_{A}(\mathrm{~N})$ & 2.07 & 1.99 & 4.15 & 4.14 & 2.56 & 2.37 & 2.76 & 2.77 \\
\hline$u_{B l}(\mathrm{~N})$ & 2.88 & 2.88 & 2.88 & 2.88 & 2.88 & 2.88 & 2.88 & 2.88 \\
\hline$u_{B h}(\mathrm{~N})$ & 1.44 & 1.44 & 1.44 & 1.44 & 1.44 & 1.44 & 1.44 & 1.44 \\
\hline$u_{c}(\mathrm{~N})$ & 3.83 & 3.79 & 5.25 & 5.24 & 4.11 & 4.00 & 4.24 & 4.25 \\
\hline$U(\mathrm{~N})$ & 7.66 & 7.57 & 10.51 & 10.49 & 8.23 & 8.00 & 8.48 & 8.49 \\
\hline
\end{tabular}
direction in relation to the rolling direction as well as $a_{p}=0.4 \mathrm{~mm}$.

Note: $\perp$-milling direction was perpendicular to the rolling direction; $\|-$ milling direction was parallel to the rolling direction.

Table 6. Uncertainty and its components for EN AW-2024 T351, perpendicular and parallel milling

\begin{tabular}{|c|c|c|c|c|c|c|c|c|}
\hline \multirow{2}{*}{ Uncertainty } & \multicolumn{2}{|c|}{$v_{c}=100 \mathrm{~m} / \mathrm{min}$} & \multicolumn{2}{|c|}{$v_{c}=500 \mathrm{~m} / \mathrm{min}$} & \multicolumn{2}{|c|}{$v_{c}=1000 \mathrm{~m} / \mathrm{min}$} & \multicolumn{2}{|c|}{$v_{c}=1500 \mathrm{~m} / \mathrm{min}$} \\
\hline & $\perp$ & $\|$ & $\perp$ & $\|$ & $\perp$ & $\|$ & $\perp$ & $\|$ \\
\hline$u_{A}(\mathrm{~N})$ & 1.17 & 1.26 & 0.90 & 0.87 & 0.95 & 0.99 & 0.89 & 0.87 \\
\hline$u_{B l}(\mathrm{~N})$ & 2.88 & 2.88 & 2.88 & 2.88 & 2.88 & 2.88 & 2.88 & 2.88 \\
\hline$u_{B h}(\mathrm{~N})$ & 1.44 & 1.44 & 1.44 & 1.44 & 1.44 & 1.44 & 1.44 & 1.44 \\
\hline$u_{c}(\mathrm{~N})$ & 3.43 & 3.46 & 3.34 & 3.34 & 3.36 & 3.37 & 3.34 & 3.34 \\
\hline$U(\mathrm{~N})$ & 6.85 & 6.92 & 6.69 & 6.67 & 6.71 & 6.74 & 6.68 & 6.67 \\
\hline
\end{tabular}
direction in relation to the rolling direction as well as $a_{p}=0.4 \mathrm{~mm}$.

Note: $\perp$-milling direction was perpendicular to the rolling direction; $\|-$ milling direction was parallel to the rolling direction.

In other cases, the uncertainty was determined analogously. Summarising, for EN AW-2017A T451 the values of expanded uncertainty $U$ ranges from 7 to $11 \mathrm{~N}$, while for EN AW-2024 T351—around 6.5 N. The uncertainty components from B method are constant for all variables. They result from the data available in the calibration certificate. The differences appear in the case of A method, which takes into account the standard deviation of the mean.

\section{Conclusions}

The conducted research and analysis of results allow to formulate the following conclusions:

- The textured surface layer after rolling was removed during milling. This type of pre-machining is often performed in industrial conditions and it is aimed at preventing of deformations of the manufactured elements, especially thin-walled ones. It is important to generate the lowest possible post-machining residual stresses. The values of these stresses are correlated, among others, with cutting resistance and therefore cutting force. The lowest cutting force values were obtained 
for the EN AW-2017A T451 alloy at $v_{\mathcal{c}}=1000 \mathrm{~m} / \mathrm{min}$, and for the EN AW-2024 T351 alloy at $v_{c}=1500 \mathrm{~m} / \mathrm{min}$, respectively.

- On the basis of results, it can also be stated that for each of applied depth of cut $a_{p}$, the lowest values of cutting forces as a function of cutting speed $v_{c}$ for individual alloys were always obtained for the same cutting speed $v_{c}$. It can be concluded that the minimum value of the cutting force as a function of cutting speed $v_{\mathcal{c}}$ is a characteristic value for a given material.

- The cutting speed $v_{c}$ for which the minimum cutting force value is obtained is a limit parameter that defines the transition from conventional machining to the High Speed Cutting. Therefore, it can be assumed that for EN AW-2017A T451 alloy, HSC occurs at $v_{c}=1000 \mathrm{~m} / \mathrm{min}$, and for EN $\mathrm{AW}-2024 \mathrm{~T} 351$ at $v_{c}=1500 \mathrm{~m} / \mathrm{min}$.

- It was also found that during milling with parallel feed direction of the cutting tool to rolling direction, the generated cutting forces were higher than for the perpendicular direction. The clear difference in the values of these forces results from the fact that only the surface layer, which is characterised by a significant anisotropy of properties in these two directions, was cut. It is also seen in the microstructure images.

- According to literature data and previously research results obtained, materials characterised by lower strength, stiffness and greater plasticity have a higher cutting speed $v_{\mathcal{c}}$ limit at which HSC occurs. From these two aluminium alloys tested, the EN AW-2017A T451 alloy is undoubtedly such a material. However, this alloy is characterised by a lower cutting speed $v_{\mathcal{C}}$ limit. Therefore, it should be considered whether it may be caused by greater stresses and deformations of the surface layer compared to the EN AW-2024 T351, which translated into hardening and strengthening of the surface layer of the EN AW-2017A T451. This thesis may be confirmed by higher cutting forces for the EN AW-2017A T451 in comparison to EN AW-2024 T351.

Author Contributions: Conceptualization, M.Z.-M., J.J., S.L., D.M., P.P. and J.P.; methodology, M.Z.-M. and P.P.; software, M.Z.-M. and P.P.; validation, J.J., S.L. and D.M.; formal analysis, M.Z.-M. and P.P.; investigation, M.Z.-M. and P.P.; resources, M.Z.-M. and P.P.; data curation, M.Z.-M. and P.P.; writing-original draft preparation, M.Z.-M. and P.P.; writing-review and editing, J.J., S.L., D.M. and J.P.; visualization, J.J., S.L. and D.M.; supervision, J.J., S.L. and D.M.; project administration, J.J., S.L. and D.M.; funding acquisition, J.J., S.L., D.M. and J.P. All authors have read and agreed to the published version of the manuscript.

Funding: The project/research was financed in the framework of the project Lublin University of TechnologyRegional Excellence Initiative, funded by the Polish Ministry of Science and Higher Education (contract no.030/RID/2018/19). The paper has been done in connection with project Innovative and additive manufacturing technology—new technological solutions for 3D printing of metals and composite materials, reg. no. CZ.02.1.01/0.0/ 0.0/17_049/0008407 financed by Structural and Investment Founds of Europe Union.

Conflicts of Interest: The authors declare no conflict of interest.

\section{References}

1. Cerutti, X.; Mocellin, K.; Hassini, S.; Blaysat, B.; Duc, E. Methodology for aluminium part machining quality improvement considering mechanical properties and process conditions. CIRP J. Manuf. Sci. Tech. 2017, 18, 18-38. [CrossRef]

2. Gao, H.; Zhang, Y.; Wu, Q.; Song, J. An analytical model for predicting the machining deformation of a plate blank considers biaxial initial residual stresses. Int. J. Adv. Manuf. Tech. 2017, 93, 1473-1486. [CrossRef]

3. Zawada-Michałowska, M.; Pieśko, P.; Józwik, J.; Legutko, S.; Mika, S.; Pytka, J. Uncertainty Estimation of Measuring Circuit During Cutting Forces Measurement Using the Piezoelectric Dynamometer. In Proceedings of the 2020 IEEE 7th International Workshop on Metrology for AeroSpace (MetroAeroSpace), Pisa, Italy, 22-24 June 2020; pp. 441-445.

4. Cui, Q.Y.; Dong, X.R.; Ma, Y.Z.E.; Liu, T.H. Application of high speed machining technology in modern die manufacture. Mater. Sci. Forum 2014, 800-801, 139-143. [CrossRef]

5. Jiang, X.; Li, B.; Yang, J.; Zuo, X.Y. Effects of tool diameters on the residual stress and distortion induced by milling of thin-walled part. Int. J. Adv. Manuf. Technol. 2013, 68, 175-186. [CrossRef] 
6. Outeiro, J. Residual stresses in machining operations. In CIRP Encyclopedia of Production Engineering; Laperrière, L., Reinhart, G., Eds.; Springer: Berlin, Germany, 2018; pp. 1-13.

7. Luo, M.; Chong, Z.; Liu, D. Cutting Forces Measurement for Milling Process by Using Working Tables with Integrated PVDF Thin-Film Sensors. Sensors 2018, 18, 4031. [CrossRef]

8. Li, Y.; Zhao, Y.; Fei, J.; Zhao, Y.; Li, X.; Gao, Y. Development of a Tri-Axial Cutting Force Sensor for the Milling Process. Sensors 2016, 16, 405. [CrossRef] [PubMed]

9. Liang, Q.; Zhang, D.; Wu, W.; Zou, K. Methods and Research for Multi-Component Cutting Force Sensing Devices and Approaches in Machining. Sensors 2016, 16, 1926. [CrossRef]

10. Liu, M.; Bing, J.; Xiao, L.; Yun, K.; Wan, L. Development and Testing of an Integrated Rotating Dynamometer Based on Fiber Bragg Grating for Four-Component Cutting Force Measurement. Sensors 2018, 18, 1254. [CrossRef]

11. Zagórski, I.; Kuczmaszewski, J. The study of cutting forces and their amplitudes during highspeed dry milling magnesium alloys. Adv. Sci. Technol. Res. J. 2013, 7, 61-66. [CrossRef]

12. Abas, M.; Salah, B.; Khalid, Q.S.; Hussain, I.; Babar, A.R.; Nawaz, R.; Khan, R.; Saleem, W. Experimental Investigation and Statistical Evaluation of Optimized Cutting Process Parameters and Cutting Conditions to Minimize Cutting Forces and Shape Deviations in Al6026-T9. Materials 2020, 13, 4327. [CrossRef]

13. Liang, Q.; Zhang, D.; Coppola, G.; Mao, J.; Sun, W.; Wang, Y.; Ge, Y. Design and Analysis of a Sensor System for Cutting Force Measurement in Machining Process. Sensors 2016, 16, 70. [CrossRef] [PubMed]

14. Urbikain Pelayo, G.; Olvera Trejo, D. Model-based phase shift optimization of serrated end mills: Minimizing forces and surface location error. Mech. Syst. Signal Process. 2020, 144, 106860. [CrossRef]

15. Tsai, C.-L.; Liao, Y.-S. Prediction of cutting forces in ball-end milling by means of geometric analysis. J. Mater. Process. Technol. 2008, 205, 24-33. [CrossRef]

16. Urbikain Pelayo, G. Modelling of static and dynamic milling forces in inclined operations with circle-segment end mills. Precis. Eng. 2019, 59, 123-135. [CrossRef]

17. Zhao, Y.; Zhao, Y.; Liang, S.; Zhou, G. A high performance sensor for triaxial cutting force measurement in turning. Sensors 2015, 15, 7969-7984. [CrossRef]

18. Totis, G.; Adams, O.; Sortino, M.; Veselovac, D.; Klocke, F. Development of an innovative plate dynamometer for advanced milling and drilling applications. Measurement 2014, 49, 164-181. [CrossRef]

19. Yaldız, S.; Unsacar, S.; Saglam, H.; Isık, H. Design, development and testing of a four-component milling dynamometer for the measurement of cutting force and torque. Mech. Syst. Signal Process. 2007, 21, 1499-1511. [CrossRef]

20. Liu, M.; Zhang, Z.; Zhou, Z.; Peng, S.; Tan, Y. A new method based on Fiber Bragg grating sensor for the milling force measurement. Mechatronics 2015, 31, 22-29. [CrossRef]

21. Klocke, F.; Gierlings, S.; Adams, O.; Auerbach, T.; Kamps, S.; Veselovac, D.; Eckstein, M.; Kirchheim, A.; Blattner, M.; Thiel, R.; et al. New Concepts of Force Measurement Systems for Specific Machining Processes in Aeronautic Industry. Procedia CIRP 2012, 1, 552-557. [CrossRef]

22. Xie, Z.; Lu, Y.; Li, J. Development and testing of an integrated smart tool holder for four-component cutting force measurement. Mech. Syst. Signal Process. 2017, 93, 225-240. [CrossRef]

23. Oczoś, K.; Kawalec, A. Manufacturing of Light Metals; Wydawnictwo Naukowe PWN: Warsaw, Poland, 2012. (In Polish)

24. Lu, L.X.; Sun, J.; Li, Y.L.; Li, J.F. A Theoretical Model for Load Prediction in Rolling Correction Process of Thin-Walled Aeronautic Parts. Int. J. Adv. Manuf. Tech. 2017, 92, 4121-4131. [CrossRef]

25. Zawada-Michałowska, M.; Kuczmaszewski, J.; Legutko, S.; Pieśko, P. Techniques for Thin-Walled Element Milling with Respect to Minimising Post-Machining Deformations. Materials 2020, 13, 4723. [CrossRef] [PubMed]

26. Polish Committee for Standardization. European Standards. Aluminium and Aluminium Alloys-Chemical Composition and Form of Wrought Products-Part 1: Numerical Designation System; PN-EN 573-1:2006; Polish Committee for Standardization: Warsaw, Poland, 2006.

27. Polish Committee for Standardization. European Standards. Aluminium and Aluminium Alloys-Sheet, Tape, Plate-Part. 2: Mechanical Properties; PN-EN 485-2+A1:2018-12; Polish Committee for Standardization: Warsaw, Poland, 2006.

28. Tool Catalogue of GARANT. Available online: https://www.hoffmann-group.com/GB/en/houk/hoffmanngroup/brands/garant/e/117408/ (accessed on 30 September 2020). 
29. Instruction of Piezoelectric Dynamometer of Kistler. Available online: https://www.kistler.com/en/ (accessed on 10 October 2020).

30. Jozwik, J.; Jacniacka, E.; Ostrowski, D. Uncertainty measurement with the kinematic telescopic bar during industrial robot inaccuracy tests. In Proceedings of the ITM Web Conf. II International conference of computational methods in engineering science (CMES'17), Lublin, Poland, 23-25 November 2017; Volume 15, pp. 1-6.

Publisher's Note: MDPI stays neutral with regard to jurisdictional claims in published maps and institutional affiliations.

(C) 2020 by the authors. Licensee MDPI, Basel, Switzerland. This article is an open access article distributed under the terms and conditions of the Creative Commons Attribution (CC BY) license (http://creativecommons.org/licenses/by/4.0/). 